\title{
sciendo
}

\section{New approaches to customer experience: where disruptive technological innovation meets luxury fashion}

\author{
Jacqueline-Nathalie HARBA \\ Bucharest Academy of Economic Studies, Bucharest, Romania \\ jacqueline_harba@yahoo.com
}

\begin{abstract}
Consumer behavior is shifting radically with the rise of e-commerce and new technologies. As a result, luxury retailers are forced to embrace a variety of technologies to keep their customers engaged. How do brands captivate shoppers and provide the customer experience that will satisfy their desires? Through dissemination of literature and case studies on examples from the industry, this paper presents a detailed discussion on the new approaches to customer experience in the luxury fashion industry, in the context of a modern economy that is highly shaped by disruptive technological innovations. The discussion includes two detailed case studies, focusing on two key themes that define contemporary customer expectations: the story - discussing customer's desire to be immersed in the narratives behind catwalk collections, and the experience - discussing the use of technology to create a unique retail space through the use of online and mobile specific technologies. The first case study focuses on how new technologies provide brands with new opportunities to present their products through narratives. Using famous luxury retailers Dior, Givenchy and Prada as examples, the case study provides a detailed discussion on the use of virtual reality and augmented reality as tools that enable customers to project themselves into the story behind a catwalk show and become active characters in the narrative, through the use of technological devices. The second case study focuses on the importance of merging the online and the traditional brick-and-mortar store. "The Store of the Future", by luxury retailer Farfetch is used as an example of how retailers make use of high-tech equipment, virtual reality and augmented reality not only to create a tech-powered interactive experience that will intrigue customers, but also to improve retail productivity by capturing customer data. The study adopts a qualitative research method to evaluate the validity of the concepts discussed in the Literature Review, using a sample of three in-depth interviews with industry experts, focusing on the use of technology to improve customer experience in physical retail spaces. Based on previously published research, it is estimated that the primary research will indicate that it is not the use of technology that drives the customer experience, but customer expectations that determine the adoption and adaptation of disruptive technologies to satisfy the shoppers' requirements.
\end{abstract}

Keywords: customer experience; luxury fashion; technological innovation; experiential shopping; virtual reality; augmented reality

\section{Introduction}

Even though 92 percent of luxury sales today still take place in brick and mortar stores, published research indicates beyond doubt that e-commerce is increasingly setting the standards of what consumers expect their shopping experience to be like (Pezzini, 2018). Changes in consumer culture, alongside the rise and continuous progress of new technologies have re-shaped all aspects of human life, including the luxury fashion industry, leaving retailers with no other option, but to adjust to a fast-evolving business model. (Pezzini, 2018) 
The luxury fashion industry is increasingly defined by the "reinvention of the customer experience, through online and offline integrations." (FARFETCH, n.d.)

What theorists referred to as the future of retail a few years back has very rapidly become the present of retail: the online and offline have converged, with new technologies shaping the customer experience and driving shoppers' purchase decision not only online, but also in physical retail spaces. (Grewal, Roggeveen, \& Nordfalt, 2017, pp. 4-5) If a brand wants to assure competitive advantage and sustainable growth, they have to constantly embrace change and use technology to dissolve temporal or geographical boundaries, in order to deliver the experience that customers require.

The new luxury shopper demands speed, interactive experiences, more shopping channels, personalization, as well as rewards for their loyalty. (Pezzini, 2018) Or in other words, the new fashion consumer is in search for a deeper connection with brands, a connection that goes beyond purchasing items, and focuses more on "experiences, quality, and the feelings that luxury products bring to their purchase." (Pezzini, 2018) The Literature Review begins with a theoretical discussion on experiential retailing and experiential marketing, as the "key" that retailers use to achieve competitive advantage and create a memorable customer experience. (Konuk, 2017, pp. 67-68)

In the context of a luxury fashion industry that has been criticized for being slow to adapt to consumer demands, the main hypotheses in this research paper is that disruptive technologies ought to be used in order to create a unified customer experience across different shopping channels: online, mobile, in-store and last, but not least, in the customers' homes, through the use of virtual reality and augmented reality headsets. (Business Insider Intelligence, 2016) Since artificial intelligence, virtual reality and augmented reality are relatively new topics, the literature discussing their impact on consumer psychology is limited. In 2015, only a few years back, theorists, such as Phyllis G. Tortora, were discussing the importance of social media, e-commerce and the rise of "wearable technology", expressing their regret for ending "this exploration of the interweaving of technology, dress and fashion at a time when so much is yet to come." (Tortora, 2015, p. 228)

Secondly, by drawing on up to date journal articles and articles from specialized publications, such as "Business Insider", "Business of Fashion", "Fashion Tech" and "Deloitte", trend forecasting websites "LS:N Global" and "Mintel", as well as presentations from famous technology-focused conferences, such as "FashionTech Berlin", the study is going to provide an overview of the new business model that the rise and evolution of VR and AR has set for the luxury fashion industry.

Thirdly, two case studies are used as a research method, aiming to create an "empirical enquiry that investigates a contemporary phenomenon within its real-life context." (Yin, 1984, p. 23) A detailed analysis of the three in-depth interviews with industry experts will be integrated within the case studies to add depth and validity to the various arguments made and examples provided throughout the research paper.

\section{Literature review}

Experiential shopping

Experiential shopping has been identified as the $21^{\text {st }}$ century "answer to retail success, through a combination of personable data, algorithms, and supercomputers." (Sterlacci et al., 2017, p. 13) As the term itself suggests ("experiential", derived from "experience", noun, 
"something that happens to you and affects how you feel" (Cambridge Dictionary, 2018)) experiential marketing has been defined as an experience that enables target consumers to actively interact with products and experience them for future purchases. (Konuk, 2017, p. 68) In other words, experiential marketing is about creating narratives around a product, about taking its essence and developing it into "a set of tangible, physical, interactive experiences which reinforce the offer." (Williams, 2006, p. 485) Stores are no longer seen as pure shopping spaces, but as experience hubs, where consumers are engaged and thrilled through multisensory marketing strategies. (Konuk, 2017, p. 68) Before discussing the role of new technologies in experiential marketing, this paper is going to firstly provide a few examples of retailers that use traditional strategies that turn simple shopping into an entertaining, memorable experience.

Famous fashion retailers such as Topshop, G-Star and Nike are only a few examples of brands that use entertainment-oriented strategies, such as live music and in-store prize draws, to turn the shop floor into an arousing environment that excites shoppers. American clothing brand Abercrombie and Fitch is a famous example of retailer that effectively uses experiential marketing to attract their target market, namely young consumers, with all its stores being similar to "a night club with low level lighting" and loud music. (Konuk, 2017, p. 69) Industry experts talk about the effect of music on shoppers' psychology, explaining how retailers use "sound to shape consumer environments" and generate more sales. (Anthes, 2010) Even though individuals might not consciously pay attention to the background songs in a store, research indicates that "behind the scenes" of shoppers' minds, music overstimulates their brain and has a very powerful influence on their purchase decisions (Khan, 2016) (Anthes, 2010) In his book "Pursuit of Silence", Brooklyn-based author George Prochnik talks about the rationale behind the loud music in A\&F stores: shoppers "make more impulsive purchases when they're overstimulated." (Anthes, 2010) In other words, as Kathleen Vohs, associate professor of marketing at the University of Minnesota explains, "loud volume leads to sensory overload, which weakens self-control"; the loud music in a store pushes shoppers outside the boundaries of conscious decision-making, "into a less deliberate mode of decision-making," where they are more vulnerable towards being attracted by brand names, fooled by special offers on products that they do not want or need, "and susceptible to other influences." (Anthes, 2010)

Niketown, Nike's famous flagship store located at Oxford Circus in London, is another iconic example of a retail space that has been turned into an experiential delight "with multimedia simulations, high-ceiling architectural design and museum-like atmosphere." (Konuk, 2017, p. 69) With all the different trial zones, such as the running trial zone and the indoor football pitch, Niketown allows customers to not only try on the product, but put it "through its paces" and experience it in an environment that simulates "the surface you play on to ensure" the perfect fit. (Nike, 2018)

Now more than ever before, there is a high pressure on companies to deliver a customer experience that "makes them stand out from their competition." (Hyken, 2018) Market research indicates that today, "89\% of companies compete primarily on the basis of customer experience", compared to only $36 \%$ in 2010 , with customer experience being the number one factor that determines a customer's decision to continue shopping from a brand. (Hyken, 2018) On one hand, the widespread availability of new technologies has re-shaped customer expectations: today's shoppers demand a seamless, personalized experience across all channels; they expect brands to know who they are and fulfil their demands immediately, 
regardless of the channel they are using. (Hyken, 2018) On the other hand, it is also new technologies that provide the solution, by offering brands innovative opportunities to engage with customers and stand out in the contemporary competitive business climate. (Hyken, 2018)

The use of virtual reality and augmented reality as experiential marketing tools

PICBE | 743

Even though the association between the fashion industry, virtual reality and augmented reality is still at its infancy, technology under different shapes and forms has been present in fashion for many years. In 2001, the launch of the North Face MET5, a heat-generating jacket marked the beginning of a new era, in which wearable technology has become a significant segment in the fashion industry. (Sterlacci et al., 2017, p. 26) Referred to at the time as "the jacket of the future", the MET5 "paved the way for other wearables" and intelligent clothing, such as smart watches that can be used to "communicate with friends, make retail payments, stream music and photos and run a variety of apps"; digital bracelets that "monitor exercise routine and heart rate"; and smart T-shirts that use technology to "monitor a wearer's biological and physiological information." (Sterlacci et al., 2017, p. 26) The borderline between technology, fashion, healthcare and fitness has been blurred for many years, creating new opportunities for designers and retailers, as well as completely re-shaping the way individuals consume products.

Virtual reality is a rapidly growing market, with an estimate of 200 million VR headsets sold to consumers by 2020, totaling \$21.8bn USD. (Rojahn, 2017) Even though at their early stages, theorists argue that virtual reality (VR), augmented reality (AR) and mixed reality (MR) marketing create new opportunities for brands to reach their consumers and engage them in conversation, having the power to dramatically "transform the way people will consume content." (Sterlacci et al, 2017, p. 14) Through the use of VR and AR "the brand's identity can take the shape of every consumer's personality"; this provides a highly personalized experience, by enabling consumers to establish an emotional connection with the brand (Toma, 2018, p. 46)

In a presentation during the FashionTech Berlin conference in January 2017, Anna Rojahn, Berlin-based freelance writer and entrepreneur, founder of six high-tech hardware companies provided a detailed insight on the influence that augmented and virtual reality have on the way individuals consume fashion globally. (Rojahn, 2019) (Rojahn, 2017) She argues that as a society, "we have a paradigm shift ahead of us in terms of how we consume media", which has a direct impact on how we consume things as well, including fashion (Rojahn, 2017) The consumer trends are divided into four main eras, strongly linked to technological innovations: the first era is characterized by offline boutiques and offline commerce; the second era started with the rise and rapid development the Internet and ecommerce; the third era has been determined by the use of mobile phones, which attracted the rise of mobile commerce; and last, but not least, the new business model, shaped by augmented and virtual reality headsets. (Rojahn, 2017) In a culture where the consumer mind is highly stimulated by experiential marketing, as discussed in detail earlier in this chapter, augmented and virtual reality offer brands new perspectives on how they present their products through narratives, enabling shoppers to project themselves into the story and become active characters through the use of technological devices. (Rojahn, 2017) The figure bellow provides a visual representation of the key paradigm shifts discussed in this paragraph. 


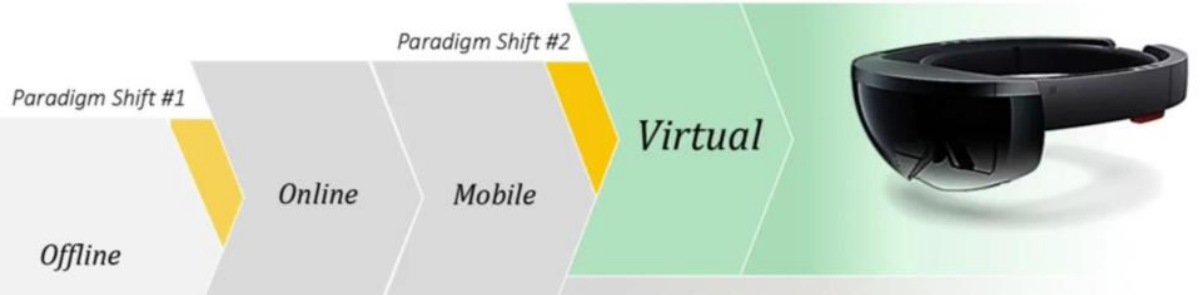

PICBE $\mid 744$

Figure 1. Paradigm shifts in consumer trends

Source: (Rojahn, 2017)

In order to be able to develop a detailed discussion on VR and AR, it is essential to firstly define the terms and understand how they alter and interfere with the real world, as we experience it, through the use of high-tech equipment. The perceived reality is the real world that we live in; virtual reality is a parallel universe, purely digital and entirely disconnected from the perceived reality, which individuals enter through VR headsets; at the borderline between the two, there is augmented reality, which is mixing elements of the real world with imaginary projections, through the use of technological devices, such as smartphones or tablets (Rojahn, 2017) The figure below is a visual representation of the three realities, representing how they interfere with each other.

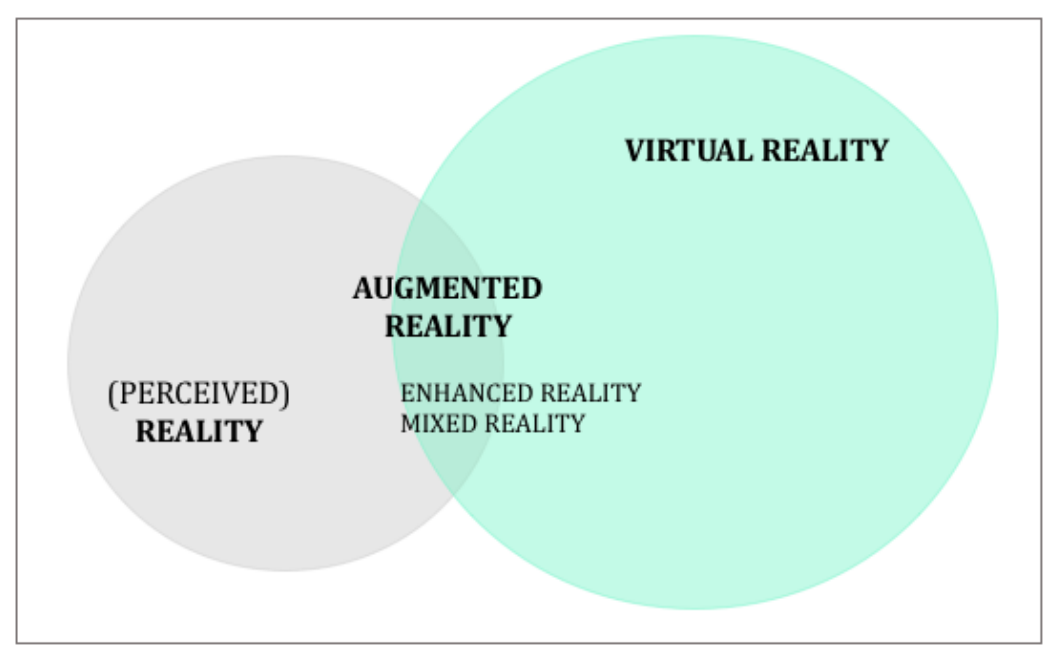

Figure 2. The three realities experienced by the modern consumer

Source: (Rojahn, 2017)

Earlier in this research paper, when discussing theories on experiential marketing, the Nike flagship store has been referenced as an example of a retail space that goes beyond the boundaries of a traditional boutique. The retailer creates an immersive customer experience by allowing customers to test the products in designated areas that simulate a football pitch or a running field. (Nike, 2018) Whilst the size of the Nike store made it possible for the brand to create these physical trail zones, the beauty of technology such as virtual reality is that it enables retailers to simulate environments and create unlimited narratives within in very limited physical spaces. Retailers can now use technology for storytelling and for presenting products in a manner never experienced before, without any special, 
contextual or environmental limitations, which is essential in an industry that "lives through storytelling" (Rojahn, 2017)

Similarly, some of the world's iconic high-end fashion designers have swapped the traditional catwalk for complex settings that engage the public in spectacular narratives. For the Autumn 2015 fashion show in New York, designer Tommy Hilfiger presented the audience with what the press has described as a "fun-filled American football extravaganza", turning the catwalk into a football pitch, the backstage into a locker room and the models into quarterbacks. (Fox, 2015) For his last show as the Creative Director of Louis Vuitton in 2013, Marc Jacobs swapped the traditional catwalk for an impressive "mise en scene" incorporating an old fashioned caged hotel elevator, escalators, a carrousel and a fountain, all in real-life size. (Armstrong, 2013) In 2014, for the Paris Fashion Week show of high-end brand Chanel, Creative Director Karl Lagerfeld turned the catwalk into a simulation of a supermarket - the Chanel Market, with aisles, shelves that were fully stocked with groceries, cashiers and shopping baskets. (Manthorpe, 2014) The way virtual reality and augmented reality are changing the fashion industry is by enabling designers to really immerse customers and clients, "no matter whether we're talking B2B or B2C" and bring them into another world, but without the efforts, costs and special requirements of creating the physical setting, like the examples discussed above. (Rojahn, 2017) The setting can go back to that of a traditional catwalk, limited in space and with very minimalistic décor, and the narrative with all its elements can be virtually created through VR headsets. More examples will be provided later in this paper through the use of case studies.

How responsive are consumers to new technologies and how eager are they to embrace virtual reality and augmented reality in their everyday lives? Theorists argue that "enjoyment and usage are the key elements that influence consumers' acceptance of new technologies" and research conducted in 2016 by Touchstone Research, famous American online research firm, specialized in innovation and technology, in partnership with Greenlight VR demonstrates the real-life validity of the argument (Katerattanakul et al., 2003) A sample of over 2,000 consumers who have recently experienced VR have been involved in a Virtual Reality Consumer Sentiment Survey asking them "to describe their feelings about the experience." (Burch, 2016) The analysis of the responses revealed that the most common terms used by the respondents were adjectives with positive connotations, such as cool, "like, awesome, excited and fun." (Burch, 2016) Another valuable fact that the study revealed is related to the age group of the people interested in new technologies: in spite of previous claims that "the experience of virtual reality is most interesting and appealing to young people", Touchstone Research revealed that the audience "extends far beyond that demographic." (Burch, 2016) Even though the way people engage with new technologies differs by generation, VR enthusiasm has been expressed by individuals from all generational groups: Generation Z (aged 10-17), Millennials (18-34), Generation X (3550) and Baby Boomers (51-69). (Burch, 2016)

The study also indicates that $95 \%$ of respondents across all age groups are aware of recent technology VR developments and $80 \%$ feel positively about trying branded VR tactics. (Burch, 2016) Moreover, the survey also revealed 81\% of surveyed individuals told their friends about their VR experience and $79 \%$ of those that have tried VR would like to try it again. (Burch, 2016) Figure 3 has been created to visually represent the findings of the survey. 


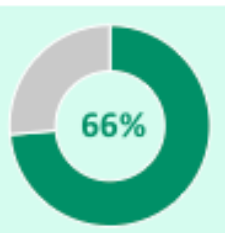

Are interested in watching TV and videos using VR technology

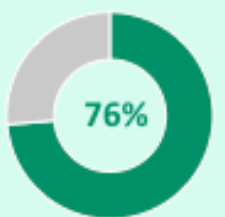

Of Generation Z consumers are interested in trying interactive experiences

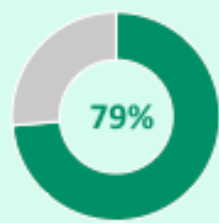

Of those who have tried VR would like to try it again

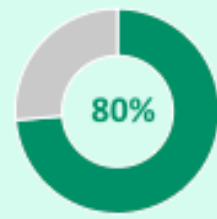

Feel positively about trying branded VR tactics

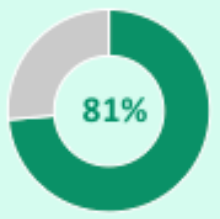

Of those that try VR tell their friends about it

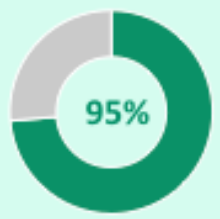

Are aware of recent technology VR developments

PICBE $\mid 746$

Figure 3. Consumer interest in virtual reality

Source: Adapted from (Burch, 2016)

Having presented a theoretical perspective on the application of new technologies in experiential marketing in the fashion industry, as well as previous market research in the field, the next chapters of this paper are going to provide a detailed discussion on the methodology and results of new qualitative research conducted by the author.

\section{Methodology}

This paper adopts a qualitative research design. Data were collected through a set of two research case studies and a total of three in-depth interviews with industry experts. Results are used to demonstrate the real-life applicability of the previously discussed theories, as well as to further explore the use of new technologies in the fashion industry, by providing concrete examples and analyzing their implications on both fashion producers and consumers. Quotes from the interviews are used in the case studies to add depth and credibility.

\section{Data collection procedures Case studies}

Case study research is one of the most commonly used qualitative research methods in business and management disciplines. (Myers, 2013, p. 82) Theorists identify two main applications of research cases, depending on how extensive the existing body of literature on the subject is. (Myers, 2013) The first one is in exploratory research, used when writing about a fairly new topic, where there is limited published literature to make reference to. (Myers, 2013, pp. 75-76) In this case, research studies are particularly useful in the exploratory phase to discover and present new "relevant features, factors or issues." (Myers, 2013, p. 75) The second application is in explanatory research, "where there is already a large body of literature on the subject" and the case studies are used to test, explain or compare theories, as well as to demonstrate that "the theory has a practical application and bring the subject matter to life." (Myers, 2013, pp. 75-76) When looking at case studies as a qualitative methodology it is essential to acknowledge that, regardless of the type of research exploratory or explanatory, the focus is on 'what' is studied, where the "what are contemporary real-life situations", "empirical evidence from real people in real-life organisations" that the researcher witnesses and describes, but has no control over. (Myers, 2013, pp. 75-76)

Given the nature of the topic, the present paper makes use of case studies both as a tool for explanatory and exploratory research, each focusing on a specific theme. "Case Study 
1. The story: the customer becomes part of the narrative" serves an explanatory purpose, building on theories discussed in the Literature Review and providing concrete examples of the different applications of VR and AR in the luxury fashion industry. On the other hand, case study 2 serves an exploratory purpose by collating and presenting a number of new disruptive technologies, that promise to completely change the way retailers sell, as well as the way shoppers consume fashion.

PICBE $\mid 747$

One of the main advantages of case study research, as well as one of the main reasons why this method has been used for the present paper is that it enables researchers to further explore theories, as well as discover new hypotheses, whilst capturing the "complexities of real-life situations", so that a given phenomenon "can be studied in greater levels of depth." (Myers, 2013) (Research Methodology, 2019)

However, the weaknesses of the methodology must also be considered. Some of the disadvantages associated with case studies include lack of rigor, time restrictions and challenges related to data analysis, such as loss of focus and subjectivity. (Myers, 2013) (Research Methodology, 2019) As a result, when used as a stand-alone method, case studies could be seen as an unreliable source that provides "very little basis for generalizations of findings and conclusions." (Research Methodology, 2019) One of the ways to overcome these weaknesses is to adopt a mixed research design, which combines case studies with other primary research methods that will enhance credibility and turn the study into "an original contribution to knowledge." (Myers, 2013, p. 76) For this precise reason, the present paper also employs in-depth interviews with industry experts, as another qualitative research method.

\section{Interviews}

Structured interviews with industry experts have been used as a method to balance the theoretical approach of this study with real-life examples and opinions. Open-ended questions have been used for all interviews, with the scope of "gaining a deeper contextual understanding of the research topic" by allowing the respondents to express themselves at length. (Toma, 2018, p. 51) (Collins, 2010, p. 136) Interviews have been identified as one of the most important and reliable "data gathering techniques for qualitative researchers in business and management", due to the fact that they allow the researcher to collect rich data from relevant individuals and gain an invaluable insight perspective "on the subject's world." (Myers, 2013, p. 119) Rubin et al., 2005 use an interesting metaphor to describe the vital importance of interviews in qualitative research by comparing them to night goggles that enable "us to see that which is not ordinarily on view and examine that which is looked at but seldom seen." (Rubin et al., 2005, p. VII) In other words, unlike survey research, in which all participants answer the same set of questions, qualitative interviews enable the researcher to engage the respondent in an extended discussion that is unique, resulting in a narrative that reflects their knowledge and professional experience. (Rubin et al., 2005, p. 4)

As a research method, the structure of the interview has been divided into research areas, in line with the different themes evidenced through the case studies. This has been done to ensure collection of relevant data, as well as to facilitate integrating the results of the interviews in the case studies. Firstly, a list of areas in which further information is required has been made; each of these areas has then been transformed into actual questions. The table below showcases the process of identifying the areas that require further investigation 
and turning these themes into generic questions that have then been personalized to reflect each of the respondents' professional background.

Table 1. The process of turning areas of investigation into interview questions

\begin{tabular}{|c|c|}
\hline Areas in which further information is required & Generic Questions \\
\hline $\begin{array}{l}\text { Disruptive technologies causing changes in customer } \\
\text { experience }\end{array}$ & $\begin{array}{l}\text { How would you say that the rise and progress in technology has changed the customer experience in the } \\
\text { fashion industry in recent years? }\end{array}$ \\
\hline $\begin{array}{l}\text { Possibility of creating immersive in-store experiences } \\
\text { through new technologies }\end{array}$ & $\begin{array}{l}\text { What would you identify as the most efficient technologies used by fashion retailers to create an } \\
\text { immersive customer experience in-store? }\end{array}$ \\
\hline Speed: the see it now, but it now culture & $\begin{array}{l}\text { How would you say that consumers' constant demand for speed and immediacy has changed the } \\
\text { traditional business model in the fashion industry? }\end{array}$ \\
\hline \multirow{2}{*}{$\begin{array}{l}\text { Willingness of fashion retailers to use Virtual Reality and } \\
\text { Augmented Reality }\end{array}$} & $\begin{array}{l}\text { How would you say that the use of VR and AR in physical stores has changed the fashion industry from a } \\
\text { retailer's perspective? }\end{array}$ \\
\hline & How willing are retailers to integrate new technologies, such as AR and VR in their marketing strategies? \\
\hline $\begin{array}{l}\text { Willingness of customers to engage with new } \\
\text { technologies }\end{array}$ & $\begin{array}{l}\text { How responsive would you say shoppers are to new technologies used by retailers in their marketing } \\
\text { strategies? }\end{array}$ \\
\hline Impact of use of technology on sales & $\begin{array}{l}\text { Would you say that the use of new technologies to create a memorable customer experience also has an } \\
\text { impact on sales? }\end{array}$ \\
\hline Future of fashion retail & $\begin{array}{l}\text { Based on the current technological trends in the fashion industry, what would you predict the future of } \\
\text { retail is? }\end{array}$ \\
\hline
\end{tabular}

Source: Author's own research

Structured interviews have been chosen over semi-structured or unstructured interviews, in order to ensure consistency across all three interviews. (Myers, 2013, p. 122) Ensuring that all three interviews follow the same structure was essential, given the rationale behind the methodology - that of dividing the script into specific areas, and the plan of later on formulating the results and discussion following the same division into different themes. Whilst consistency across interviews is one of the major advantages of a structured interview, this could also be seen as a disadvantage: maintaining a strict script interferes with the open dialogue between the interviewer and the interviewee, which may lead to an inability to "pursue any new lines of enquiry that might emerge during the course" of the conversation. (Myers, 2013, p. 122) However, this risk has been reduced to a minimum through rigorous research on the respondents' professional background prior to conducting the interviews, and ensuring that the questions are adapted accordingly. This has allowed the interviewees to provide answers that are personal to their experience, whilst adhering to the researcher's initial plan.

In order to ensure a good variety of opinions, the respondents chosen for this research have different professional backgrounds, either in fashion or in the development of technology solutions and VR, all relevant to the research topic of this paper. The first respondent, referred to as $\mathrm{R} 1$ is an academic, working as a Lecturer at University for the Creative Arts, London, United Kingdom, teaching across various Undergraduate and Postgraduate courses in the Business School. The second respondent, referred to as R2 works as the Country Director (UK) at Devatics, a French company with pan-European representation, developing omni-channel software for fashion retailers. In the United Kingdom, the company works with some of the biggest fashion retailers in the market, 
including British premium brands such as Phase Eight, Whistles, Karen Millen, Jigsaw, Coast, L.K. Bennett, Thomas PINK and Radley \& Co. The third respondent, referred to as R3 is a psychology graduate, VR expert and young entrepreneur, owner of UniVRse gaming studio. Based in Bucharest, UniVRse is Romania's largest VR gaming studio, equipped with the latest innovations in the field, such as the KatWalk platform, which offers users a much more intense and realistic experience compared to traditional virtual reality goggles. (UniVRse, 2019) Even though the latter respondent's background is not linked to fashion, his knowledge of technology and understanding of the VR market, as well as consumer behaviour has brought key contributions to this study.

\section{Results and discussions}

\section{Case study 1. The story: the customer becomes part of the narrative}

Earlier in the Literature Review, it has been argued that new technologies offer brands new perspectives on how they present their products through narratives, enabling the shopper to project themselves into the story and become active characters through the use of technological devices. (Rojahn, 2017)

The question is, what is the profile of the brands that are most willing to integrate new technologies in their marketing strategies? Drawing on his vast experience working as a technology provider for fashion retailers in the UK market, respondent R2 argues that the answer lies in the original format of the business - whether the business was originally a brick-and-mortar (selling only in physical stores) or pure play (selling solely online). He explains that each type of retailer has something to learn from the other, both still having flaws and weaknesses in their strategies.

"In my experience, brands who have started off life in physical stores, moving into online, then multichannel are much slower to adopt leading edge in-store tech compared to businesses that have grown up as digitally centric and moved into physical retail. Yet both types of business are playing catching up. The traditional businesses are re-purposing their systems to improve their omni-channel capability to compete with the digital-centric 'new girls in town' and the new digital businesses are yet to gain critical mass in physical retail and have adequate physical manifestation of their brand to take ground from the traditional retailers."

The worlds' most renowned luxury fashion houses are traditionally rooted in the high-street; when selling expensive, high-end products, great emphasis is being put on a sense of exclusivity and one-to-one interaction between the shop assistant and the consumer, which could be one of the reasons why, in spite of having access to the necessary funds, luxury brands are much slower at embracing technology than newer, younger high-street brands. (Locke, 2018)However, in recent years, more and more luxury brands started collaborating with technology companies to incorporate technology in the retail spaces, as well as their catwalk shows and marketing campaigns. This is an effect of retailers' acknowledgement that, as argued in the literature review, customer experience is the most important factor influencing a shopper's decision whether to continue shopping with a brand or not. (Hyken, 2018) R2's opinion sustains the validity of the argument: he argues that the need for technology is an effect of changes in consumer behavior, that it is "the customer demands and expectations that drive the technology and its adoption." He continues by stating that "the business that does not put the customer at the center of what it does and adapt itself 
rapidly through the use of technology to fit in is the next casualty on the list." In other words, embracing and using technology is not optional, but compulsory for business survival.

Part of French multinational luxury goods group LVMH, Christian Dior is renowned for its ability to bring innovation to the catwalk each season, which also explains why Dior has been one of the first fashion houses to acknowledge that new technologies "are the future of the fashion industry" and embracing them "will help meet the needs of their customers." (Sterlacci \& Arbuckle, 2017, p. 26) In 2015, Dior was the first global luxury fashion brand to launch "Dior Eyes", its own VR headset developed in partnership with French technology developer DigitasLBi Labs France. (LVMH, 2015) Dior were not the first to use VR technology. French fashion house Yves Saint Laurent used the Google Glass headset in the past to give customers make-up tutorials. (Boxall, 2015) For its fall collection in 2015, American premium clothing company Tommy Hilfiger incorporated Samsung Gear VR headsets in select stores globally to enable customers to watch a three-dimensional version of its catwalk show as if they were sat front row (Arthur, 2015) One of the first designers to use VR in its marketing strategy, Tommy Hilfiger himself identified the great potential that the technology has as an experiential marketing tool that brings the "one-of-a-kind fashion show to the retail setting", offering "a compelling and interesting elevation of the traditional shopping experience." (Arthur, 2015) In 2016, Balenciaga, luxury brand owned by the French multinational company Kering also used VR to make the experience of their fashion shows available to customers worldwide. (Morozova, n.d.) However, Dior were indeed the first to recognize the opportunity of not just using VR technology, but completely blurring the line between fashion and technology and designing their very own VR headset. (Boxall, 2015)

The headset acts as a personal VIP pass, welcoming customers into the backstage of a Dior fashion show and enabling them to experience the pre-show atmosphere with all its elements. (Boxall, 2015) It seamlessly combines the two worlds, that of couture fashion and innovative technology. From a functionality point of view, the headset "is equipped with highdefinition image resolution and integrated holographic audio", creating a 3D image of the backstage of a Dior fashion show. (LVMH, 2015) Using $360^{\circ}$ vision, the headset lets visitors move around and experience all the details in a virtual universe. (LVMH, 2015) From a design point of view, the device is an expression of "the superb craftsmanship" that Dior is renowned for, all in glossy black, with the Dior logo in white across the front of the headset. (LVMH, 2015) Even though the headset is not for sale and is only available to be used in selected Dior stores across Europe, the launch of the headset is still an important milestone when looking at technological innovations in fashion historically.

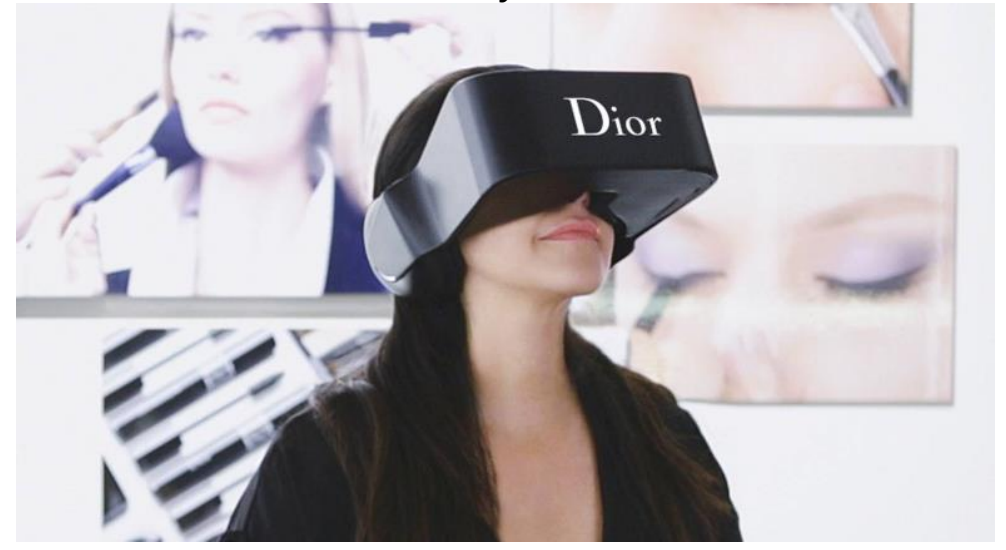

Figure 4. Dior virtual reality headset 
In 2017, a couple of years after the launch of the Dior Eyes, another LVMH brand made an announcement that excited technology and fashion enthusiasts alike: luxury fashion house Givenchy and Korean design studio PDF House announced that they are working on a new device that combines VR and AR technology. (Damiani, 2017) Even though the headset is still at a conceptual level and has not yet been released in the market, the mockup has been received with great enthusiasm, described as the "facelift" of immersive technology. (Damiani, 2017) From a technical perspective, the Givenchy headset is the first one that promises to allow the consumer to oscillate between VR and AR by simply flipping the lenses on the same device. (Damiani, 2017) From a design perspective, it is interesting to observe how much the style has progressed compared to the Dior headset, moving towards a smaller size, with "high-end, ready-to-wear chic" features that perfectly match the Givenchy aesthetic. (Damiani, 2017) Whilst the Dior glasses still look very similar to those launched by technology companies in previous years, the Givenchy glasses put great emphasis on "timeless styling, including bold, elegant colors and interplay of tones" and could be easily worn as an every-day accessory. (Damiani, 2017) Figure 5 is one of the advertising mockups that PDF Haus launched in November 2017, a visual that could undoubtedly fit inside the covers of any world-renowned fashion magazine.

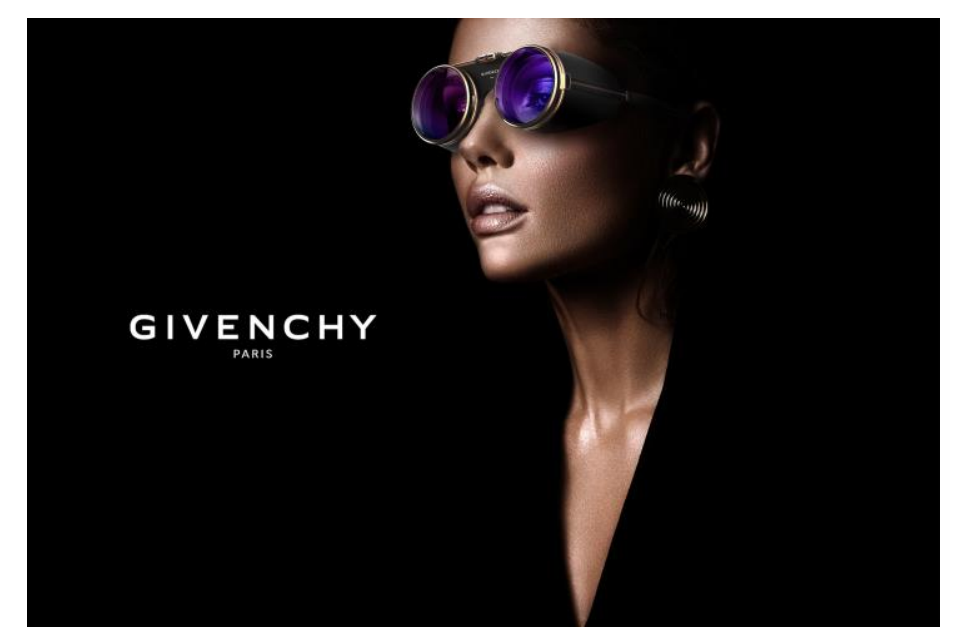

Figure 5. Givenchy x PDF Haus VR/AR headset mockup

Source: (Damiani, 2017)

Whilst Dior and Tommy Hilfiger use VR to diversify the in-store experience by giving shoppers access to catwalk shows and exclusive backstage footage that they would not have access to otherwise, other designers created mobile apps that make it possible for customers to be immersed into the narrative from the intimacy of their own homes. (DV, 2016) In December 2016, famous Italian luxury brand Prada marked the launch of its "La Femme Prada" and "L'Homme Prada" fragrances with an interactive app, "Prada x Prada" used to promote the two perfumes. The app is available for download on Oculus Store, App Store and Google Play Store and requires the use of a VR headset to become fully immersive. (DV, 2016) Using VR technology, the app takes users on a digital journey through "a transitional series of scenes and experiences" offering a glimpse "into the narrative and aesthetic codes" of the fragrances. (Les Facons, 2016) Produced in partnership with DVgroup, the 3D animation film flawlessly combines virtual reality, 3D sound and stereoscopic technologies to project the 
spectator in a unique three-dimensional universe of "collages, optical illusions, reflections, diffractions, trompe-l'œil and infinite or monumental aspects." (DV, 2016)

As evidenced in the literature review, the popularity of augmented reality is on the rise, with more and more fashion houses using the technology in their catwalk shows and even embedding the technology in the design of their garments. A particularly interesting example that ought to be considered is British retailer Marks \& Spencer's augmented reality childrenswear T-shirt collection, launched in 2016. While all the examples referred to in this study target adult luxury goods consumers, the M\&S collection is a particularly interesting example due to the fact that it is aimed at young consumers, boys and girls, aged 5 to 14 . (M\&S, n.d.) Each T-Shirts has prints of different animals that come to life when scanned through the free Wear 4D+ application, either using a smartphone or a tablet, putting on a circus-worthy performance that excites the really young consumers. (M\&S, n.d.) The figure below is one of the images used by M\&S to promote the collection when it first launched.

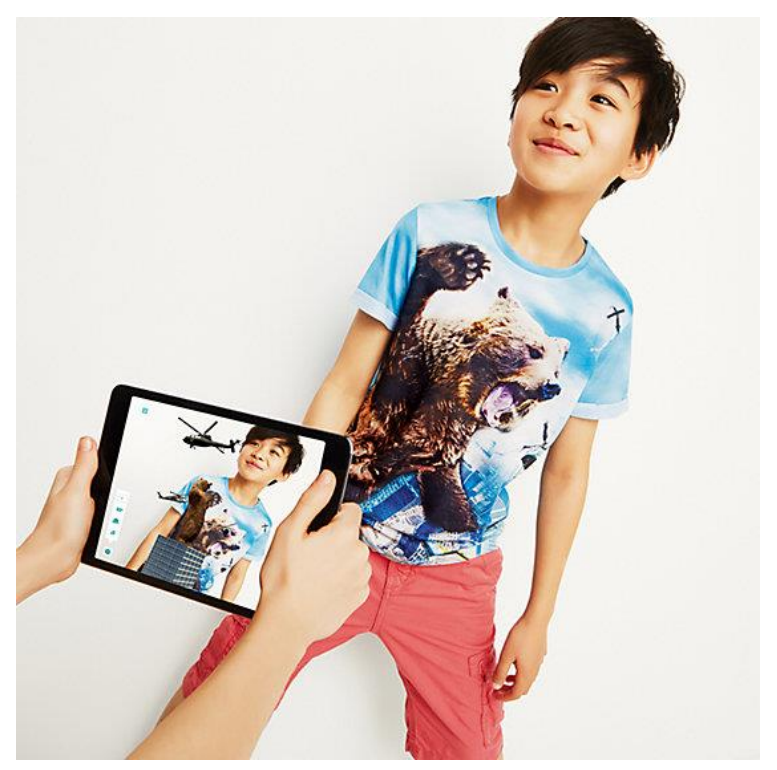

Figure 6. M\&S children's augmented reality T-Shirt

Source: (M\&S, n.d.)

Looking at the M\&S campaign from a retailer's perspective, it is perfectly understandable that brands choose to target younger generations through the use of technology and gaming, considering that research indicates that Generation Z (aged 10-17) are amongst the most enthusiastic VR users. (Burch, 2016) This argument has also been sustained by results of primary research conducted for this paper: referring to the Romanian VR gaming market, and drawing on his experience as a technology expert and entrepreneur, respondent R3 identified younger consumers, aged 9 to 14, as the main target consumer for VR games: "they spend most of their time playing computer games with their friends and are familiar with VR from watching many vloggers playing VR games on YouTube."

\section{Case study 2. The experience: the store of the future}

The use of virtual reality has completely re-shaped the traditional business model in the fashion industry, by enabling brands to create a more personal connection with the 
consumer. Respondent R3 explains that VR is such an efficient tool for experiential shopping due to the fact that it helps the customer have a more personal interaction with a product:

"If you see a 3D version of the product and analyse it from a different perspective than the 2D photo that we are used to, you have more information that influences your decision. Volvo made a test a few months ago, in which they presented a new car model using VR and concluded that the sales increased significantly when the buyers were presented with a VR simulation of the car's environment."

However, VR is far from being the only disruptive technology changing the customer experience in luxury fashion.

When asked about popular technologies used by retailers to create an immersive customer experience in-store, respondent R1 referred to the comeback of the QR code in the Asian market. One could argue that this is a very surprising answer, considering that most individuals would now regard QR codes as an old technology. However, R1 insists that, in the context of a fashion industry that increasingly demands transparency in regard to the supply chain and production cycle, one of the functions of QR codes is to act as digital labels, providing customers with all the details on the garments they are purchasing: "where the garment was sourced, who made it, how much they were paid, how sustainable the distribution chain is, etc." Compared to other technologies, QR codes could indeed be seen as less innovative; however, their role in keeping the shopper informed is beyond doubt a key element for a good customer experience.

In case study 1 , the Marks \& Spencer childrenswear collection has been used as an example of how retailers use augmented reality to create an immersive customer experience. Respondent R1 also spoke about companies that started experimenting with forms of virtual fitting rooms using both VR and AR technology. One of the most iconic projects to date is "The Store of the Future", owned by online luxury fashion retail platform Farfetch.

Web analytics data indicate that Farfetch is the world's leading online destination for luxury shopping, measured by traffic, "outperforming competitors including Yoox Net-aPorter and Neiman Marcus." (Kansara, 2017) Founded in 2007 by Jose Neves, the Farfetch marketplace offers over 3,200 different luxury brands, divided across categories including Ready to Wear, Vintage, Fine Watches and Fine Jewellery, all shipped to 190 countries around the world. (FARFETCH, n.d.) The retailer is a good example of a brand that came to life online and then moved into physical retail, using all its digital capabilities to create an immersive in-store experience like no other luxury brand has to date. Unlike other brands, such as Kohl, Missguided, Dr. Martens, luxury British retailer Burberry and many others that use techdriven props such as interactive screens, digital mirrors, "mannequins with screens on their foreheads", and other "gimmicky" technology that is "more likely to drive short-term PR" than actual in-store sales, Farfetch's store is designed to capture invaluable customer data and improve human interactions between shop assistants and shoppers, which will lead to improved retail productivity and increased sales. (Kansara, 2017)

In April 2017, Farfetch unveiled their innovative concept to the public for the very first time during the FarfetchOS conference, at the Design Museum in London. (Kansara, 2017) The concept was firstly implemented in London-based boutique Browns, in autumn 2017, then launched in Thom Browne's flagship store in NY in March 2018. (Kansara, 2017) (FARFETCH, n.d.)

Farfetch refer to their initiative as the "Augmented Retail vision", "taking the magic of the physical store experience and bringing it together with the advantages in the online and 
digital experience." (FARFETCH, n.d.) In other words, the Store of the Future is a 'fusion' between online, offline and mobile: shoppers download the Farfetch app on their smartphone, which holds records of their online browsing and purchase history, as well as their in-store shopping behavior. (Mortimer, 2017)

As soon as the customers walks into the store, the shop assistant is notified of the arrival of a connected customer. (Mortimer, 2017) The shop assistant can then view the customer's profile, gaining insight into their shopping behavior, wish list and purchase history; understanding the complete customer profile enables "store staff to provide a more tailored, personalized and high level of service," which, according to respondent R2 is key in today's customer-centric culture: (Mortimer, 2017)

"Consumers have almost infinite choice these days and where alternatives are just a few clicks or swipes away, they expect not to have to tell you (talking about fashion retailers) anything. You should already know everything about them and they expect every product to be available through every channel, via every delivery or collection method and fast (...) Make them work too hard to buy from you and they are gone, possibly for good!"

The store also uses advanced technology for the clothing rails, meaning that any item that shoppers look at in-store is recognized, recorded and immediately linked to the mobile app, creating an in-store browsing history that is added to their customer profile. (Mortimer, 2017) Moreover, the mirror in the changing room is far from the ordinary mirrors used traditionally in retail stores: the 'mirror of the future' displays a digital wish list, enabling the customer to "request different sizes, colours, items." (Mortimer, 2017) The mirror has a product recommendation system, similar to the online software generating personalized product recommendations on websites; the product suggestions that appear on the mirror while the shopper is in the changing room are personalized, "based on the customer's personal style, previous purchases and browsing history." (Mortimer, 2017)The customer can simply press on the digital mirror to request to try on one of the recommended products, ask for a different size and even purchase the items. (Mortimer, 2017)

What would be the most valuable feature of this new concept? The answer could be summed up in two words: consistency and communication. More specifically, the great success of Store of the Future is owed to the efficient communication between all the different systems - the website, the app, the digital mirror, the checkout, which allows for a complete customer profile to be created and used for consistent, personalized customer targeting across all channels. (Kansara, 2017)

Figure 7 below showcases the personalized greeting message and product recommendations, as they appear on the digital mirrors used in the Store of the Future. 


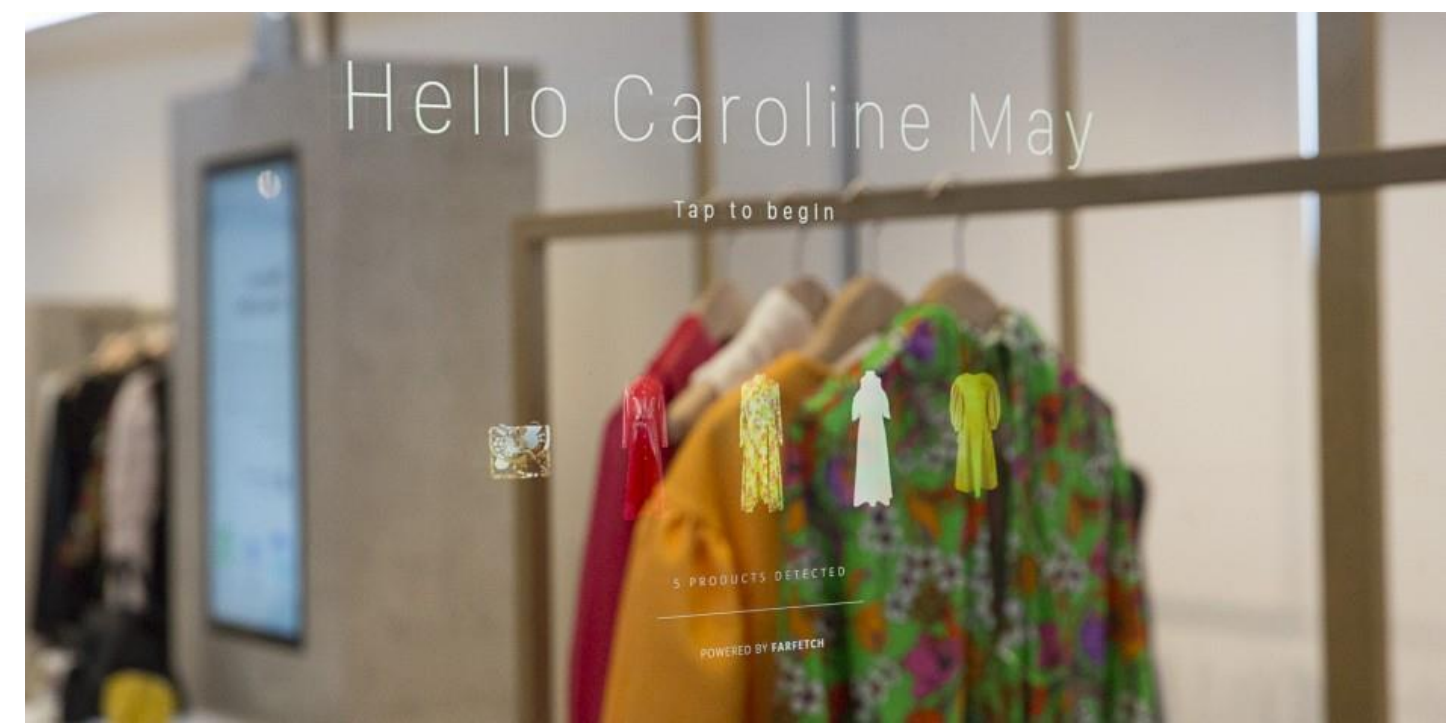

PICBE | 755

Figure 7. Farfetch interactive digital mirror

Source: (Mortimer, 2017)

Why was there a need for a Store of the Future in the luxury market? In an interview with Business of Fashion, Farfetch Founder and CEO Jose Neves discuses three key facts: the first one is that "digital is completely influencing consumer behavior and the creation of desire" - idea that was also evidenced in the Literature Review of this paper, when discussing individuals' willingness to engage with VR, as revealed by the Touchstone VR research; the second is that "online is growing much faster than offline"; and last, but not least, offline is currently, and will remain the medium "where the vast majority of transactions take place." (Kansara, 2017) Taking these three facts into consideration, Neves concluded that the future of luxury retail lies in "augmented retail", namely the fusion between online, offline and mobile, which is the core concept of the initiative.

\section{Conclusion}

This paper has discussed disruptive technologies that are re-shaping the customer experience in luxury fashion. An in-depth discussion of literature has been provided, with multiple references to examples from the industry to support these theories. A key term that also needs to be addressed when thinking about the topic critically is "disruptive", with its different meanings. According to the definition provided in the Cambridge Dictionary, disruptive, adjective, has two different definitions: one with a positive connotation, "changing the traditional way that an industry operates, especially in a new and effective way"; and one with a negative connotation, "causing trouble and therefore stopping something from continuing as usual." (Cambridge Dictionary, 2018) The question is, when using the adjective in the present context, which of the two connotations is most appropriate? Taking the path of this research paper, technological innovations most certainly bring a positive contribution to the luxury fashion industry, both for consumers and for retailers. As discussed throughout the literature review and case studies, technology supports retailers in collecting valuable customer data, as well as "plays an important role in increasing revenues and decreasing costs." (Inman et al., 2017) On the other hand, technology also enables customers to receive the memorable experience that they lust after. However, could one also associate the intensive use of technology with negative effects, such as the loss of human interaction and 
communication? What will happen to the employment rate globally, if employees are gradually being replaced by machines? These are important issues that ought to be considered in future research.

Thinking about the psychological implications of the M\&S collection, as well as other similar ones, raises questions about how "healthy" the excessive use of technology is for such young subjects. Even though not the main focus in this particular research paper, the effects of technology on consumer psychology is a topic that must be addressed in future extensions of this research paper.

To conclude, this study has demonstrated that the future of luxury retail is defined by the seamless integration of the offline, traditional brick and mortar store, with technologies specific to the online environment. Both published literature and the results of the qualitative research conducted for this paper indicate that customer consumption trends drift towards the use of new technologies, which forces brands to adapt to the new business model in order to survive in the competitive landscape of the fashion industry.

Looking at all the different examples introduced through the case studies particularly those of designers using virtual technology to enable the customer to experience fashion shows, which are traditionally exclusive to celebrities and press, as though they were sat front row, we could argue that aside from offering a seamless customer experience, technology has another key role - that of bringing the brand closer to the customer, which establishes a bond that is more personal than ever before.

One of the major limitations of this study is that it adopts a qualitative research design, that focuses on presenting information and evidence from an industry perspective, rather than from a consumer's perspective. Considering that both published literature and the results of the primary research indicate that customer expectations dictate the adoption and adaptation of technology amongst luxury fashion retailers, it is vital for future quantitative research to be conducted amongst luxury fashion consumers, aiming to gain a better understanding on the issue from a shopper's perspective.

\section{References}

Anthes, E. (2010). Outside In: It's So Loud, I Can't Hear My Budget! Retrieved 12 18, 2018, from Psychology Today:

https://www.psychologytoday.com/intl/articles/201009/outside-in-its-so-loud-icant-hear-my-budget

Armstrong, L. (2013). Paris Fashion Week: Marc Jacobs's last show for Louis Vuitton. Retrieved 12 22, 2018, from The Telegraph: http://fashion.telegraph.co.uk/newsfeatures/TMG10349944/Paris-Fashion-Week-Marc-Jacobss-last-show-for-LouisVuitton.html

Arthur, R. (2015). Hands-On With Tommy Hilfiger's In-Store Virtual Reality Catwalk Experience. Retrieved 12 28, 2018, from Forbes: https://www.forbes.com/sites/rachelarthur/2015/10/25/hands-on-with-tommyhilfigers-in-store-virtual-reality-catwalk-experience/\#49dbfabb3ee4

Boxall, A. (2015). This VR headset is your backstage pass to a top fashion show. Retrieved 12 28, 2018, from Digital Trends: https://www.digitaltrends.com/mobile/dior-eyesvr-fashion-show-headset-news/

Burch, A. (2016). VR AND CONSUMER SENTIMENT. Retrieved 12 16, 2018, from Touchstone Research: https://touchstoneresearch.com/vr-and-consumersentiment/ 
Business Insider Intelligence. (2016). More retailers are adopting AR and VR technology. Retrieved 11 22, 2018, from Business Insider: https://www.businessinsider.com/more-retailers-are-adopting-ar-and-vrtechnology-2016-6

Cambridge Dictionary. (2018). Retrieved 12 04, 2018, from Cambridge Dictionary: https://dictionary.cambridge.org/dictionary/english/disruptive

Cambridge Dictionary. (2018). Retrieved 12 04, 2018, from Cambridge Dictionary: https://dictionary.cambridge.org/dictionary/english/experience

Chandler, M. (2016). Apple, Facebook, Alphabet Ride Virtual Reality. Retrieved 12 05, 2018, from Investor's Business Daily: https://www.investors.com/news/technology/apple-facebook-alphabet-ridevirtual-reality/

Charara, S. (2018). Fashion Week's new fling? Augmented reality comes into focus. Retrieved 12 29, 2018, from Wearable: https://www.wareable.com/fashion/fashion-week-augmented-reality-aw-2018

Collins, H. (2010). Creative Research. The Theory and Practice of Research for the Creative Industries . London: AVA Books.

Damiani, J. (2017). These Givenchy VR Concept Glasses Pack The Best of Sci-Fi Luxury. Retrieved 12 28, 2018, from VR Scout: https://vrscout.com/news/givenchy-vrglasses-sci-fi-luxury/

DV. (2016). Prada - The Interactive Virtual Experience Prada x Prada. Retrieved 12 29, 2018, from DV: https://dv.fr/dvcreative/projects/pradaxprada/

FARFETCH. (n.d.). Store of the Future. The Augmented Retail Vision. Retrieved 01 05, 2019, from FARFETCH: https://aboutfarfetch.com/about/store-of-the-future/

FashionUnited. (2017). Timeline: 70 years of Christian Dior. Retrieved 12 29, 2018, from Fashion United: https://fashionunited.uk/news/fashion/timeline-70-years-ofchristian-dior/2017030723778

Fox, I. (2015). Tommy Hilfiger scores touchdown with football-themed show at New York fashion week. Retrieved 12 22, 2018, from The Guardian: https://www.theguardian.com/fashion/2015/feb/17/tommy-hilfiger-footballshow-new-york-fashion-week

Grewal, D., Roggeveen, A. L., \& Nordfalt, J. (2017). The Future of Retailing. Journal of Retailing, 93(1), 1-6.

Hyken, S. (2018). Customer Experience Is The New Brand. Retrieved 12 28, 2018, from Forbes: https://www.forbes.com/sites/shephyken/2018/07/15/customerexperience-is-the-new-brand/\#693ff5317f52

Inman, J. J., \& Nikolova, H. (2017). Shopper-Facing Retail Tech- nology: A Retailer Adoption Decision Framework Incorporating Shopper Attitudes and Privacy Concerns. Journal of Retailing, 93(1), 7-28.

Kansara, V. A. (2017). Inside Farfetch's Store of the Future. Retrieved 01 05, 2019, from Business of Fashion: https://www.businessoffashion.com/articles/bofexclusive/inside-farfetchs-store-of-the-future

Katerattanakul, P., \& Siau, K. (2003). Creating a virtual store image. Communication of the ACM, 46(12), 226-232.

Khan, H. (2016). How Retailers Manipulate Sight, Smell, and Sound to Trigger Purchase Behavior in Consumers. Retrieved 12 18, 2018, from Shopify Blogs: https://www.shopify.com/retail/119926083-how-retailers-manipulate-sight-smelland-sound-to-trigger-purchase-behavior-in-consumers

Konuk, F. A. (2017). Competitive Strategies in Retailing in Emerging Economies: Evidence from Turkey. In V. Nadda, S. Dadwal, \& R. Rahimi, Promotional strategies and New Service Opportunities in Emerging Economies (pp. 66-90). Hershey: IGI Global.

Les Facons. (2016). Prada x Prada Interactive App. Retrieved 12 29, 2018, from Les Facons: https://lesfacons.com/2016/12/12/prada-X-prada-interactive-app/ 
Locke, G. (2018). A luxury brand looks to technology to thrive in the digital age. Retrieved 12 29, 2018, from Digital Commerce 360:

https://www.digitalcommerce360.com/2018/07/31/a-luxury-brand-looks-totechnology-to-thrive-in-the-digital-age/

LVMH. (2015). Dior creates its own virtual reality headset. Retrieved 12 28, 2018, from LVMH: https://www.lvmh.com/news-documents/news/dior-creates-its-ownvirtual-reality-headset/

M\&S. (n.d.). Augmented Reality Aliens T-Shirt (5-14 Years). Retrieved 12 29, 2018, from M\&S: https://www.marksandspencer.com/xmas-aliens-augmented-reality-t-shirt-514-years-/p/p22491845

Manthorpe, R. (2014). MODEL SHOPPERS: CHANEL SHOW OFFERS SUPERMARKET CHIC. Retrieved 12 22, 2018, from LS:N Global:

https://www.lsnglobal.com/news/article/15341/model-shoppers-chanel-showoffers-supermarket-chic

Morozova, A. (n.d.). Ready for the First Row at a Fashion Show? Retrieved 12 29, 2018, from Jasoren: https://jasoren.com/pret-pour-la-premiere-ligne-au-defile-dior/

Mortimer, N. (2017). Farfetch has created an operating system for bricks and mortar retail in its new 'Store of the Future' platform. Retrieved 01 05, 2019, from The Drum: https://www.thedrum.com/news/2017/04/18/farfetch-has-created-operatingsystem-bricks-and-mortar-retail-its-new-store-the

Myers, M. D. (2013). Qualitative Research in Business \& Management. Second Edition. London: SAGE Publications.

Nike. (2018). Retrieved 12 08, 2018, from Nike: https://www.nike.com/us/en_us/retail/en/niketown-london

Pezzini, G. (2018). 6 technology trends reshaping the luxury fashion industry. Retrieved 11 24, 2018, from LS Retail: https://www.lsretail.com/blog/6-technology-trendsreshaping-luxury-fashion-industry/

Research Methodology. (2019). Case Studies. Retrieved 01 15, 2019, from Research Methodology: https://research-methodology.net/research-methods/qualitativeresearch/case-studies/

Rojahn, A. (2017). Augmented and Virtual Reality for the Fashion Industry. FashionTech Berlin.

Rojahn, A. (2019). Anna Rojahn. Entrepreneurship, Technology and Wine. Retrieved 0103 , 2019, from Anna Rojahn: https://annarojahn.com/

Rubin, H. J., \& Rubin, I. S. (2005). Qualitative Interviewing. The Art of Hearing Data. Second Edition. London: SAGE Publications.

Sterlacci, F., \& Arbuckle, J. (2017). Historical Dictionary of the Fashion Industry. Second Edition. London: Rowman \& Littlefield.

Toma, C. H. (2018). The Shop of the Future: Bridging the Online/Offline Experience Gap in Fashion Retail Through Virtual Reality. In I. R. USA, Fashion and Textiles: Breakthroughs in Research and Practice (pp. 42-69). Hershey: IGI Global.

Tortora, P. G. (2015). Dress, Fashion and Technology. From Prehistory to the Present. London: Bloomsbury.

UniVRse. (2019). Retrieved 01 15, 2019, from UniVrse: https://www.univrse.ro/desprenoi/

Williams, A. (2006). Tourism and hospitality marketing: Fantasy, feeling and fun. International Journal of Contemporary Hospitality Management, 18(6), 482-495.

Yin, R. (1984). Case Study Research: Design and Methods. Beverly Hills: Sage Publications. 